\title{
Discussion Papers in Economics \\ The Effect of Development on the Climate Sensitivity of Electricity Demand in India
}

\author{
Eshita Gupta
}

May 2014

Discussion Paper 14-05

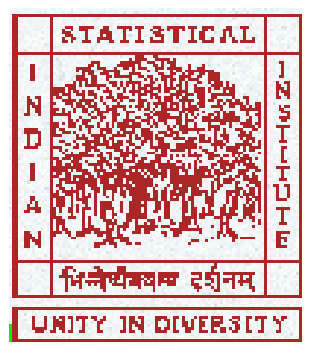

Indian Statistical Institute, Delhi

Economics and Planning Unit

7, S. J. S. Sansanwal Marg, New Delhi 110016, India 


\title{
The Effect of Development on the Climate Sensitivity of Electricity Demand in India
}

\author{
Eshita Gupta
}

May 7, 2014

\begin{abstract}
The climate sensitivity of electricity demand in India is likely to be highly sensitive to growth in income. Thus, both intensive and extensive adjustments in cooling and heating will play an important role in determining future climate change impacts on electricity demand. This chapter utilizes a national level panel dataset of 28 Indian states for the period 2005-2009 to show that (1) electricity demand is positively related to temperatures in summers and negatively related to temperatures in winters; (2) the effect of temperature increase on demand in summers is higher in a hotter climate as people adapt with the use of higher cooling equipment whereas there is a higher negative response to temperature increase in winters in colder climates as people adapt using higher heating equipment; (3) the effects of both the hotter and the colder climates on electricity demand are expected to be more pronounced at the higher income levels. The preferred estimates indicate that climate change will increase electricity demand by 6.9 percent with 4 percent p.a. GDP growth and 8.6 percent with 6 percent p.a. GDP growth in 2030 over the reference scenario of no climate change. This reflects the fact that the estimated marginal effect of a hotter climate is greater when income is higher. The results suggest that over 50 percent of the climate change impacts will be due to extensive adjustments and that electricity demand models that do not account for extensive adjustments are likely to underestimate the climate change impacts on electricity demand especially in developing countries like India where the current penetration of air- conditioning equipment is very low.
\end{abstract}

\section{Introduction}

This paper aims to understand how India's electricity demand will be affected by changes in its climate, weather and income. To what extent does the weather sensitivity of electricity 
demand depend on climate and the level of income? Due to growth, the impact of climate change in India will be time-varying. We saw in [Gupta, 2012] that the rising part of the U-shaped temperature-electricity curve of Delhi is becoming steeper over time implying an increase in cooling demand per unit increase in summer temperatures. In this paper, I extend the analysis to the all-India level, enabling the use of the large climatic and income variations across states to assess the dependence of the temperature-electricity demand relation on the level of income and climate.

I estimate the relationship between daily electricity demand, daily temperature (a key indicator of weather), climate and income across 28 spatially differentiated Indian states ${ }^{1}$ using state-level panel data for the period 2005-2009. This is the first econometric study that estimates the impact of climate change on the electricity demand in the case of India. This research is novel in that it uses high frequency daily data to analyze the dynamics of adjustment across differentiated Indian states by modeling India's electricity demand within a panel framework using state and region fixed-effect models.

The study finds that the climate sensitivity of electricity demand in India is likely to be highly sensitive to its income growth. Between 2009 and 2030, India's GDP will double if it grows at 4 percent p.a. and treble if it grows at 6 percent p.a. According to my preferred estimates, in a reference scenario with no climate change, electricity demand in India is expected to surge by 105 percent with 4 percent p.a. GDP growth and by 224 percent with 6 percent p.a. GDP growth by 2030. If India's climate warms by $1^{0} C$ during this period, then the demand for electricity is likely to increase by 119 percent with 4 percent p.a. income growth, and by 252 percent with 6 per cent p.a. income growth by 2030 . Thus, as a result of climate change, electricity demand is estimated to be 6.9 percent higher than in the reference scenario with 4 percent p.a. GDP growth and 8.6 percent higher than in the reference scenario with 6 percent p.a. GDP growth by 2030. This reflects the fact that the estimated marginal effect of a hotter climate is greater when income is higher. Over 50 percent of the climate change impacts on demand are due to extensive adjustments in cooling and heating requirements. Thus, electricity demand models that do not account for extensive adjustments are likely to underestimate the climate change impacts on electricity demand, particularly in developing countries such as India where, unlike in the case of developed countries, the penetration of cooling technologies is very low at present. In 2007, for instance, approximately only 2 percent of households had access to air-conditioners as against 87 percent in the U.S. ([Sivak, 2009]). However, in a warmer and a richer future economy, there is bound to be rapid adoption of energy-using equipment ([Wolfram et al., 2012]). [Akpinar-Ferrand \& Singh, 2010] for example, have shown air-conditioning to be a significant

\footnotetext{
${ }^{1}$ The India is made up of 27 states and one union territory, namely, Chandigarh.
} 
preventive mechanism in avoiding extremely hot days and that it should be considered a key climate adaptation strategy for India.

As I have shown in [Gupta, 2012] there is a non-linear relationship between temperature and electricity demand as the electricity demand is positively related to temperatures in summer and negatively related to temperatures in winters. Therefore, climate change is expected to reduce electricity consumption in winters and increase electricity consumption in summers. Also, climate change will affect electricity demand by changing how people will respond along both extensive and intensive margins of adjustment (see review by [Auffhammer \& Mansur, 2012]). For instance, in the short run, during summer, people may adapt by using existing cooling equipment more intensively on a hot day while, in the long run, they may choose to buy an air-conditioner to mitigate expected reduction in comfort due to changed climate [Sailor \& Pavlova, 2003]. Thus, while the long-term climate will determine the space-conditioning equipment stock in different states, the daily external weather or temperature determines the utilization of the equipment for heating or cooling. To capture both intensive and extensive adjustments due to climate change, I estimate the impact of daily weather as well as long-term climate on electricity demand in India.

This study estimates the non-linear relationship by a piecewise linear function using two segments: one for the summer where temperature is above the predetermined reference temperature, and another one for winters where temperature is below the same reference temperature. The approach assumes a V-shaped temperature-electricity curve with the minimum electricity demand point occurring at the reference temperature. I use cooling degree days (CDD) and heating degree days (HDD) that describe the deviation of daily mean temperature from a reference temperature ${ }^{2}$ as a measure of severity of hot and cold weather respectively. For this study, I estimate the transition point of electricity demand from heating to cooling as 20.3 from the observed data. This reference temperature fits the data best as it minimizes the residual sum of squares in the estimated piecewise regression. I determine the slope of the rising segment by relating daily electricity demand and daily CDD in summers. I determine the slope of the falling segment by relating daily electricity demand and daily HDD in winters.

Thus, I use the daily CDD and HDD to analyze weather-related electricity demand. The sums of daily CDD and HDD over a year constitute the indicators for heat and cold stress, respectively, as well as the description of a state's climate. I determine the cooling degree day index (CDDI) and heating degree day index (HDDI) of each state as the average

\footnotetext{
${ }^{2}$ The reference temperature is defined as the outdoor temperature at which the cooling (or heating) systems do not need to run in order to maintain comfort conditions. When the outdoor temperature is below/above the reference temperature, the cooling/heating systems need to operate, resulting therefore in increased energy requirements.
} 
of the annual cooling degree days and heating degree days, respectively, during 2005-2009 in order to analyze the impact of long-term climate on electricity demand. I allow the slope of the rising part of the curve to depend on the climate by interacting CDD with the CDDI in summers and the slope of the falling part of the curve to depend on the climate by interacting HDD with the HDDI in winters. I have utilized this method since a higher positive response to temperature increase is expected in summers in a hotter climate as people adapt by installing more cooling equipment, while a higher negative response to temperature increase is expected in winters in a colder climate as people adapt by installing more heating equipment. I also expect the effects of both the hotter and the colder climate to be more pronounced at higher income levels. [DePaula \& Mendelsohn, 2010] analyzed the interaction between income distribution and climate change impacts in Brazil using cross-sectional household level data and found that the temperature elasticity of electricity consumption varies significantly across income classes. Thus, I have included a three way interaction of CDD, CDDI and income in summers and HDD, HDDI and income in winters in the study to investigate the impact of income on the climate sensitivity of electricity demand in India.

I have conducted the climate change analysis using near-term (2030/2016-2035) and midterm (2050/2045-2065) scenarios for South Asia developed by the Intergovernmental Panel on Climate Change and that are presentated in Working Group-1 of the Fifth Assessment Report. With the whole temperature distribution shifting rightwards with global warming, there has been an increase in the cooling degree days and reduction in the heating degree days. Consequently, the CDDI will increase while the HDDI will fall. In this paper, I combine the estimated electricity demand model with predicted changes in both daily degree days and long-term climate to develop estimates of the changes related to electricity demand in India. With that aim in mind, Section 2 of the paper describes the data sources and reports summary statistics. Section 3 presents the econometric approach while Section 4 describes the results. Section 5 assesses the magnitude of my estimates of the effect of climate change. In Section 6, I present the conclusions and policy implications of my findings.

\section{Data and Summary Statistics}

\subsection{Data Sources}

I base the empirical results of the study on daily data for the period 2005 through 2009 for the 28 states. The dependent variable is the daily electricity demand of the state, measured in million kilowatt hour (MKWh), as obtained by the operator of the national electricity 
grid, the National Load Dispatch Centre (NLDC). The electricity consumption reported by the NLDC is restricted electricity demand, which is equal to the electricity supplied by the utilities. To obtain the unrestricted electricity demand, I add the state electricity supply shortage to the electricity consumption data of NLDC. For Delhi and the eastern states, I have obtained the observed daily shortage respectively from the Delhi Transco Ltd. and the NLDC. For the other states, the observed daily shortage ${ }^{3}$ data is only available from 2008 onwards; therefore, I use the monthly shortage data published by the Central Electricity Authority (CEA) of India to derive an approximate electricity supply shortage for each day for the period before 2008 .

The explanatory variables fall into three categories: (1) climate and weather variables; (2) socio-economic characteristics; and (3) seasonal factors. The first category of explanatory variables is climate and weather variables. I convert the mean daily temperature into cooling degree days (CDD) during summer (with the mean temperature above $20.3^{\circ} \mathrm{C}$ ) and heating degree days (HDD) during winter (when the mean temperature is below $20.3^{0} \mathrm{C}$ ). The CDD and HDD quantify the difference between the daily mean temperatures above or below a reference temperature. I calculate the HDD on day $d$ on the basis of the relation: $\mathrm{HDD}_{d}=\min$ $\left(0, \mathrm{~T}_{d^{-}} 20.3\right)$, where $\mathrm{T}_{d}$ is the mean temperature on day $d$. I calculate the CDD on day $d$ on the basis of the relation: $C D D=\max \left(0, \mathrm{~T}_{d}-20.3\right)$. As a measure of climate during summer, I use the average of the annual cooling degree days during 2005-2009 or the state cooling degree day index (CDDI). As a measure of climate during winter, I use the absolute value of the average of the annual heating degree days during 2005-2009 or the state heating degree day index (HDDI). I define the CDDI and HDDI as

$$
\begin{aligned}
& C D D I_{i t}=1 / 5\left(\sum_{d=1}^{d=1825} \max \left(0, T_{i d}-20.3\right)\right) \\
& H D D I_{i t}=1 / 5\left(-\sum_{d=1}^{d=1825} \min \left(0, T_{i d}-20.3\right)\right)
\end{aligned}
$$

The daily rainfall is the other weather variable. I construct both state-level daily temperature and daily rainfall using the $1^{0} \times 1^{0}$ gridded daily dataset published by the Indian Meteorological Department ${ }^{4}$ (IMD).

The second set of variables that the study uses are socio-economic variables: income,

\footnotetext{
${ }^{3}$ The daily shortage data comprises five components: shedding due to transmission and distribution constraints; shedding by discoms in theft-prone areas; shedding in order to restrict overdrawal; shedding due to grid constraints; and shedding in order to restrict under-frequency operations.

${ }^{4}$ For Delhi and Chandigarh that are not identified in this gridded dataset due to their small size, I have obtained station-level data from the website www.tutiempo.net/en/climate/India.
} 
population and electricity prices. I use the gross domestic product per capita of a state as an indicator of income and its stage of development. I take the annual real GDP (19992000 prices) of the state and population from the Ministry of Statistics and Programme Implementation. I construct the annual electricity price of the state using data from the Central Electricity Authority (CEA) of India. First, I calculate the state electricity prices for each sector - Agriculture, Commerce, Industry and Residential Use- by taking the simple average over different categories ${ }^{5}$ (voltage and phases). I construct the average electricity price for a state by taking the weighted average of the prices in these four sectors with the share of electricity sales of each sector in total sales taken as weights.

The final category of regressors consists of variables accounting for industrial seasonality and agricultural seasonality. In the agricultural sector (that accounts for 18 percent of total electricity demand), energy requirements for water-pumping depend on a state's agricultural season and rainfall pattern. To capture agricultural seasonality, I control for agricultural pumpsets and include an interaction of pumpsets with accumulated rainfall in the past 7 days. The latter determines soil moisture and, therefore, the demand for pumping. I obtain data on annual electricity using state agricultural pumpsets from the CEA. Industrial electricity consumption (that accounts for about 45 percent of total demand) is largely temperatureinsensitive. However, there can be industrial seasonality due to business cycles, dependence on agriculture for its supply of raw materials and product demand. To capture industrial seasonality, I derive a state-specific monthly index of industrial production ${ }^{6}$ (MIIP). First, I calculate the percentage deviation from the average in the MIIP at all-India level for each month and year ${ }^{7}$. I take the average of the five percentage deviations from the average in MIIP obtained for each month during 2005-2009 as an indicator of the industrial seasonality for that month at all-India level. I multiply this all-India indicator of industrial seasonality by the share of industrial electricity consumption in the total electricity consumption of a state and the share of the state's industrial output in the industrial output of India in order to get a measure of state-specific MIIP . I take the data on the all-India monthly index of industrial production and the share of the state's industrial output in the industrial output

\footnotetext{
${ }^{5}$ Since power requirement varies among consumers in terms of voltage and phases, the CEA computes the average rates of electricity supply for various categories of consumers. For instance, in the case of industries, it computes electricity prices for three different types: three-phase small-scale 400V; three-phase large-scale $11 \mathrm{KV}$, and three-phase very large-scale $33 \mathrm{KV}$. For domestic consumers, it gives prices for $230 \mathrm{~V}$ singlephase or $400 \mathrm{~V}$ three-phase used for lighting, air-conditioning, water heating, cooking, etc. For agricultural consumers, it reports prices for $230 \mathrm{~V}$ single-phase and $400 \mathrm{~V}$ three-phase used for running tube wells and pump sets. For commercial consumers, it gives prices of $230 \mathrm{~V}$ single-phase and $400 \mathrm{~V}$ three-phase used for equipment and appliances.

${ }^{6}$ Data on state-level MIIP is not available for most states.

${ }^{7}$ For instance, if in January 2005, the MIIP is 120 while the average MIIP in 2005 is 100, then the percentage deviation for January in 2005 is $+20 \%$
} 
of India from the Ministry of Statistics and Programme Implementation. I obtain the share of industrial electricity consumption in the total electricity consumption of a state from the CEA.

\subsection{Summary Statistics.}

Table (1) reports state-level summary statistics of all variables. The sample comprises a balanced panel of 28 states and a total of 51,128 observations. For each state, there are 1819 daily observations during the years 2005-2009 after allowing for the necessary lags (i.e., the sum of rainfall in the past seven days). Over the period, mean state daily electricity demand increased from $60 \mathrm{MKWh}$ in 2005 to $79 \mathrm{MKWh}$ in 2009 while the mean state daily temperature increased from 24.3 to 25 degree Celsius ${ }^{8}$. About 78 percent of the sample observations represent the cooling demand with the observed mean temperature above $20.3^{0} C$ while 22 percent represent the heating demand with the observed mean temperature below $20.3^{\circ} C$. This shows an almost equal variation in temperature in summers and winters. The average CDD is 6.8, which is higher than the average absolute value of HDD at 3.8, reflecting relatively mild winters and hot summers.

Since India, given its vast size, displays a large variation in terms of its climate among states, the CDDI too varies significantly from a low of 417 to a high of 2712 degree days. Similarly, the HDDI varies between 0 and 1927 degree days. Equally important, the real gross state domestic product per capita over the period too varies significantly, from a low of INR 7500 to a high of INR 89300. At the same time, the mean state real gross state domestic product per capita increased by 30 percent from approximately INR 25,300 in 2005 to INR 33,000 in 2009.

I plot all the states in the two-dimension space of gross domestic product per capita and climate for the year 2009. Figure (1) presents a scatter plot of state gross domestic product per capita versus CDDI. The plot shows that most states are hot with a high value of the CDDI. While the states in the top right of the scatter plot are both hot and rich, the states in the bottom right are hot but poor. Figure (2) presents a scatter plot of state gross domestic product per capita versus HDDI. The plot shows that most states (except the northern states) experience mild winters with a low value of the HDDI. The northern states, on the other hand, with both high CDDI and HDDI, are characterized by strong temperature variation during the different seasons. The southern states, with the highest CDDI and zero HDDI experience only slight seasonal variations in temperature. The western and the eastern

\footnotetext{
${ }^{8}$ The annual mean temperature of India in 2009 was about +.91 degrees Celsius above the average temperature (recorded during the 1961-1990 period) and was the warmest year since 1902. This superseded the earlier five warmest years: 2002(0.71), 2006(0.60), 2003(0.56), 2007(0.55), and 2004(0.51) (GOI 2009).
} 
Table 1: State-level Summary Statistics

\begin{tabular}{|c|c|c|c|c|c|c|c|c|}
\hline \multirow[t]{2}{*}{ Variables } & \multicolumn{3}{|c|}{ Mean } & \multicolumn{2}{|c|}{ Standard deviation } & \multirow[t]{2}{*}{ Max } & \multirow[t]{2}{*}{ Min } & \multirow[t]{2}{*}{ Obs } \\
\hline & 2005-2009 & 2009 & change & overall & Within & & & \\
\hline & & & from 2005 & & state & & & \\
\hline Daily Electricity Demand (MKWH) & 69.53 & 79 & 19 & 78.22 & 16.31 & 431.5 & 0.1 & 51128 \\
\hline \multicolumn{9}{|l|}{ Climate and Weather } \\
\hline Daily mean Temperature $\left({ }^{o} \mathrm{C}\right)$ & 24.5 & 25 & 0.66 & 5.5 & 4.9 & 39 & 0.6 & 51128 \\
\hline Daily CDD $\left([\text { Temp- } 20.3]^{*} \mathrm{D}(\mathrm{T}>20.3)\right)$ & 6.5 & 6.8 & 0.4 & 3.3 & 3 & 18.7 & .001 & 40034 \\
\hline Daily HDD $\left([\text { Temp- } 20.3]^{*} \mathrm{D}(\mathrm{T}<20.3)\right)$ & -4.3 & -3.8 & -0.6 & 3.4 & 2.7 & 0.00 & -19.7 & 11094 \\
\hline Cooling Degree Day Index (CDDI) & 1864 & 1864 & - & 542 & 0 & 2712 & 417 & 51128 \\
\hline Heating Degree Day Index (HDDI) & 328 & 328 & - & 408 & 0 & 1927 & 0 & 51128 \\
\hline Rainfall (sum of last 7 days $(\mathrm{mm})$ ) & 31.78 & 27.8 & 7 & 51.4 & 49 & 703 & 0 & 50932 \\
\hline \multicolumn{9}{|l|}{ Socio-Economic } \\
\hline GDPPC (Rs) & 29000 & 33000 & 7600 & 15315 & 3231 & 89300 & 7500 & 51128 \\
\hline Population (million) & 40.3 & 41.5 & 2.3 & 42.3 & 1.3 & 195 & 0.94 & 51128 \\
\hline Price(Paise/KWH) & 269 & 243 & -60 & 67 & 37 & 458 & 133 & 51128 \\
\hline$\%$ Villages Electrified & 83.6 & 84.6 & 2.6 & 19 & 2.3 & 100 & 30.4 & 51128 \\
\hline Agriculture Pumps (thousand) & 555.8 & 577.5 & 49.6 & 800.6 & 41.6 & 3116.6 & 0 & 51128 \\
\hline State MIIP & & & & & & 7554 & -4082 & 51128 \\
\hline
\end{tabular}

Note: All entries are simple averages over all 28 states.

states experience mild winters and hot summers while the north-eastern states experience mild winters and mild summers.

Over the five years of the study period, relatively little variation within states is evident, for population, agricultural pumpsets, percentage of villages electrified and real electricity price that are used as control variables though they vary significantly between states.

\section{Empirical Strategy}

This section describes the econometric framework that I use to assess the temperature and climate sensitivity of electricity demand. [Gupta, 2012] estimated the U-shaped temperature electricity curve that varies over time for Delhi using the semi-parametric variable coefficient approach. In this paper, I estimate the observed non-linear relationship between electricity consumption and temperature using a piecewise linear regression method. As external 
Figure 1:

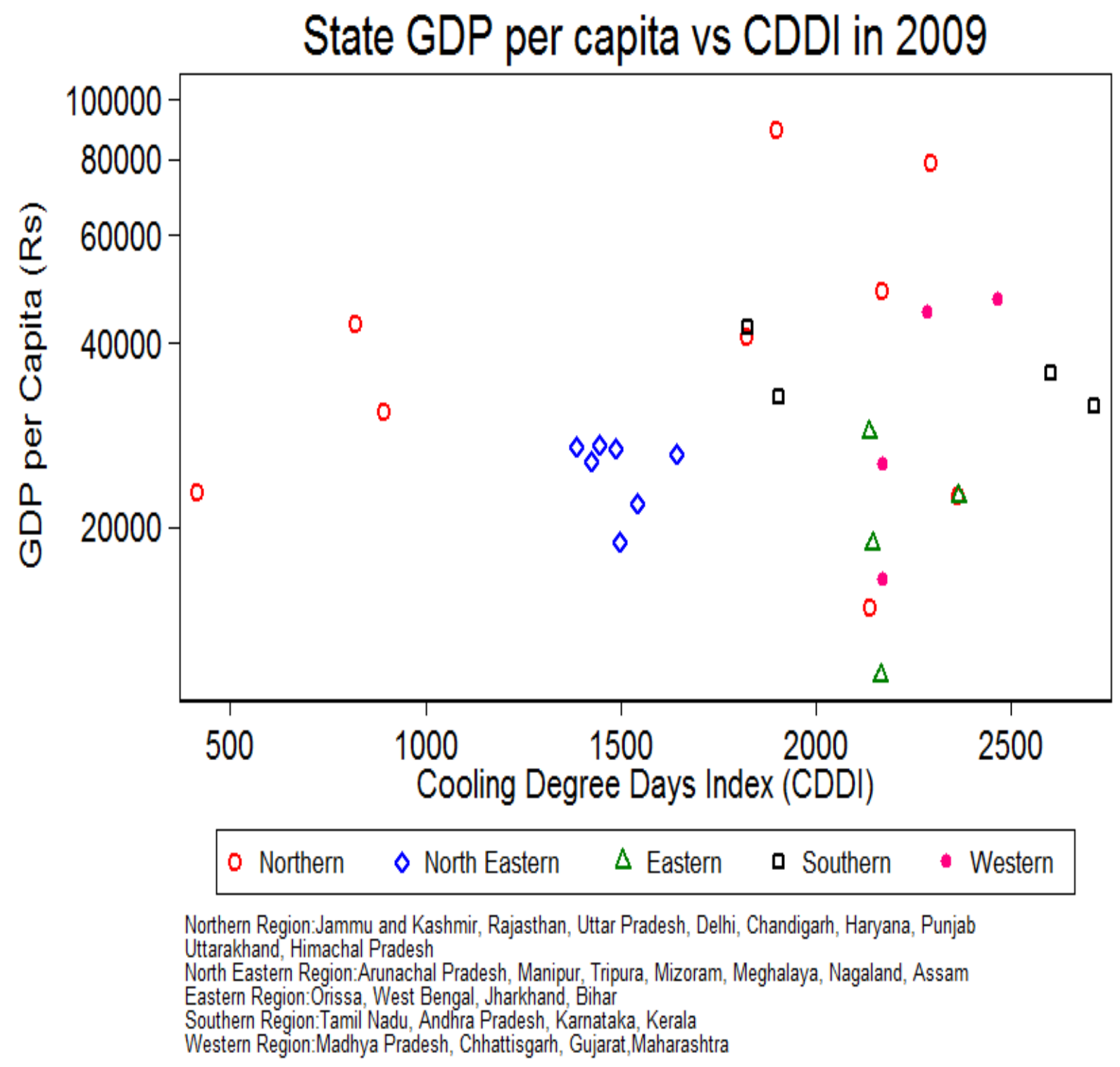


Figure 2:

State GDP per capita vs HDDI in 2009

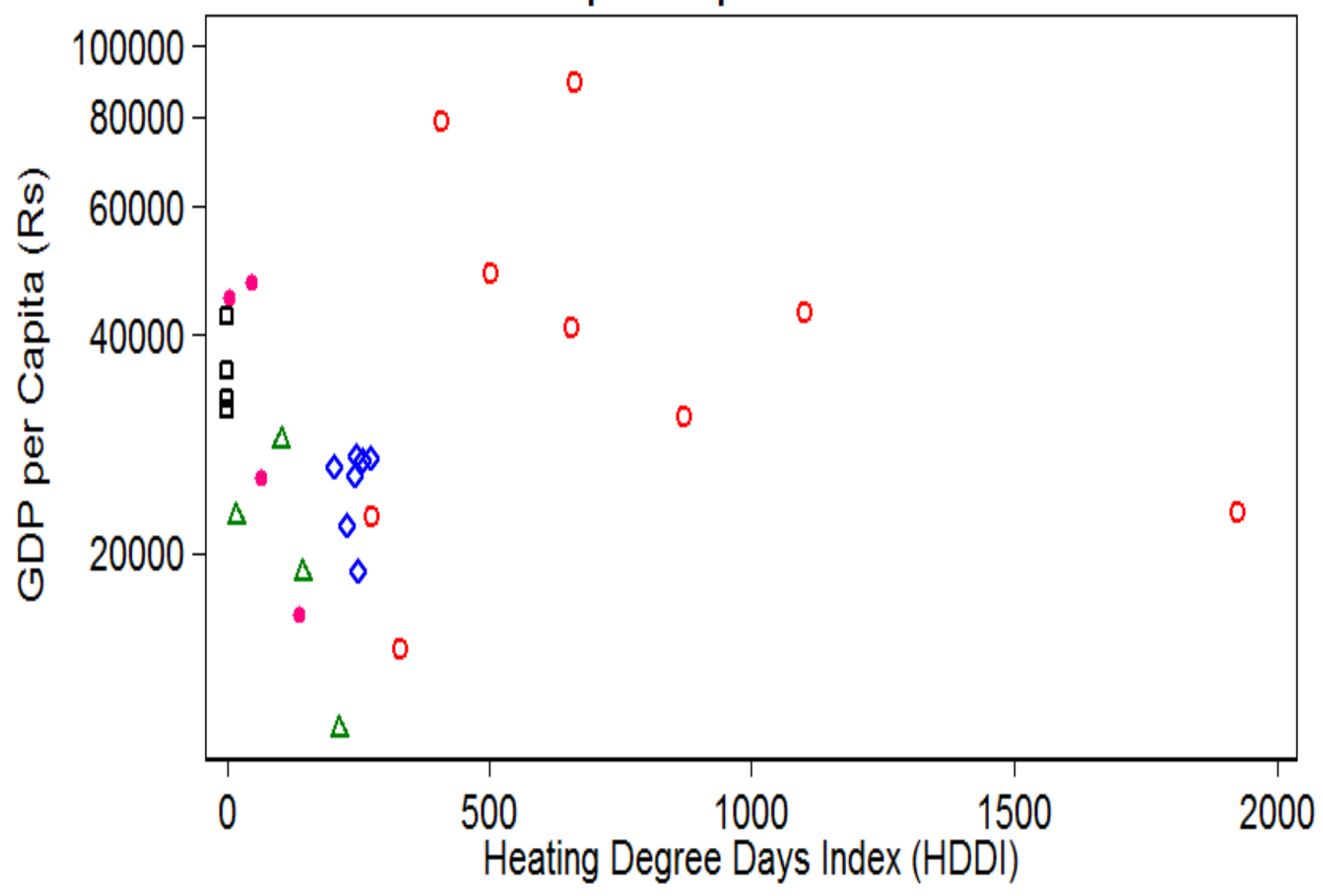

Northern Region:Jammu and Kashmir, Rajasthan, Uttar Pradesh, Delhi, Chandigarh, Haryana, Punjab Uttarakhand, Himachal Pradesh

North Eastern Region:Arunachal Pradesh, Manipur, Tripura, Mizoram, Meghalaya, Nagaland, Assam Eastern Region:Orissa, West Bengal, Jharkhand, Bihar

Southern Region:Tamil Nadu, Andhra Pradesh, Karnataka, Kerala

Western Region:Madhya Pradesh, Chhattisgarh, Gujarat,Maharashtra 
temperatures deviate above or below the reference temperature, the electricity demand increases proportionally. The V-shaped temperature-electricity curve is estimated with the minimum electricity demand point occurring at the reference temperature. I have selected the reference temperature of 20.3 Celsius as it minimizes the residual sum of squares and fits the observed data best ${ }^{9}$. I determine the upward sloping segment of the curve by regressing the daily electricity demand on the daily CDD in summers. I allow the slope of this rising segment to depend on climate and income by including interactions of CDDI and GDPPC with CDD. Similarly I determine the downward sloping segment of the curve by regressing daily electricity demand on daily HDD in winters. I allow the slope of this falling segment to depend on climate and income by including interactions of HDDI and GDPPC with HDD.

The first prediction of my empirical model is that electricity demand is positively related to temperatures in summers and negatively related to temperatures in winters. I first estimate a natural log electricity demand regression, which includes weather variables (CDD and HDD) plus controls for socio-economic characteristics and seasonal factors without interactions, as follows:

$$
\begin{aligned}
\ln \left(E_{i d}\right)= & \theta_{i}+\kappa_{Q}+v_{w}+\delta \ln \left(\text { GDPPC }_{i t}\right)+\eta \ln \left(\text { Pop }_{i t}\right)+\gamma \ln \left(\text { price }_{i t}\right) \\
& +\vartheta \ln \left(\text { Pump }_{i t}\right)+\rho \ln \left(\text { Pump }_{i t}\right) *(\text { Rain in Week })_{i d}+\omega(\text { Rain in Week })_{i d} \\
& +\pi(\text { Major Hol })_{i d}+\alpha H D D_{i d}+\beta C D D_{i d}+\varepsilon_{i d}
\end{aligned}
$$

where $\ln \left(E_{i d}\right)$ is the $\log$ of total electricity demand of a state $i$ on day $d . \theta_{i}$ is a statespecific fixed effect allowing an idiosyncratic daily electricity demand for each state. It accounts for factors such as climate, geography, state-specific policies and natural resource endowments, which are fixed for a state over time. The term $\theta_{i}$ sweeps out the variation between states with estimates based on only the variation within each state. $\kappa_{Q}$ is a quarter fixed effect allowing for general shocks in daily electricity demand affecting all states each quarter. This captures industrial and agricultural seasonality that might influence daily electricity demand during a year. $v_{w}$ is a day of week fixed effect that captures the weekly periodicity of electricity demand. For example, there may be lower demand on weekends. $\ln \left(G D P P C_{i t}\right)$ is the log of gross domestic product per capita of a state in year $t, \ln \left(P_{o p}{ }_{i t}\right)$ is the $\log$ of the population of a state in year $t, \ln \left(\right.$ price $\left._{i t}\right)$ is the $\log$ of the electricity

\footnotetext{
${ }^{9}$ The commonly used reference temperature in the literature is 18 degrees Celsius. This threshold varies from region to region. In the case of India, though I searched between $17-22^{0} \mathrm{C}$, I found the residual sum of squares to be minimum in the interval $20.3-21^{\circ} \mathrm{C}$. In chapter 2 , I found that the minimum temperature threshold interval for Delhi has shifted from approximately $20-22^{0} \mathrm{C}$ in the $2000-05$ period to about $18.5-20^{0} \mathrm{C}$ in the 2006-09 period.
} 
price of a state in year t, Major $\mathrm{Hol}$ is a dummy variable that takes the value one for a major holiday, and zero otherwise ${ }^{10}, \ln \left(\right.$ Pump $\left._{i t}\right)$ is the $\log$ of the number of electricity using agricultural pumpsets of a state in the year $t$, Rain in Week measures the sum of daily rainfall in millimeters $(\mathrm{mm})$ in the past 7 days and is interacted with the number of agricultural pumpsets. $C D D_{i d}=\max \left(0, \mathrm{~T}_{i d}-20.3\right)$ is the cooling degree days on day $d$ for state $i$. It takes a positive value in summers when temperature is above $20.3^{0} C$ and zero in winters when temperature is below or equal to $20.3^{0} C$. $H D D_{i d}=\min \left(0, \mathrm{~T}_{i d^{-}}-20.3\right)$ is the heating degree days on day $d$ for state $i$. It takes a negative value in winters and zero in summers. The last term, $\varepsilon_{i d}$, in equation (1) is the stochastic error term.

I expect $\beta>0$ and $\alpha<0$. This prediction is quite straightforward and is confirmed by the existing literature ([Al-Zayer \& Al-Ibrahim, 1996]; [Sailor \& Muñoz, 1997]; [Valor et al., 2001]; [Sailor, 2001]; [Pardo et al., 2002]; [Mirasgedis et al., 2007]).

Prediction 2 of my model states that the effect of the temperature increase in summers is generally higher in a hotter climate as people adapt with higher cooling equipment. Similarly, a higher negative response to temperature increases in winters is to be expected in colder climates as people adapt with higher heating equipment. To evaluate this prediction, I estimate Model B that includes an interaction of $C D D_{i d}$ with $C D D I_{i}$ and an interaction of $H D D_{i d}$ with $H D D I_{i}$.I estimate the model as

$$
\begin{aligned}
\ln \left(E d_{i d}\right)= & \theta_{i}+\kappa_{Q}+v_{w}+v / X_{i d} \\
& +\alpha_{1} H D D_{i d} * H D D I_{i}+\beta_{1} C D D_{i d} * C D D I_{i}+\varepsilon_{i d}
\end{aligned}
$$

where $X$ includes all controls for socio-economic characteristics and seasonal factors as in eq (1). It is worthy of note that, in Model B, I drop the independent terms of HDD and $C D D$, the reason being that the slope of the rising segment of the $\mathrm{V}$-shaped curve will be zero if the $C D D I$ is zero and the slope of the falling segment will be zero if the $H D D I$ is zero. The marginal effect of daily temperature on the $\log$ of electricity demand is $\alpha_{1} * H D D I_{i}$ if $T_{i d} \leq 20.3^{0} C$ and $\beta_{1} * C D D I_{i}$ if $T_{i d}>20.3^{\circ} C$. I expect $\beta_{1}>0$ and $\alpha_{1}<0$. I base the estimates of $\beta_{1}$ and $\alpha_{1}$ in this model on within-state variations in $C D D$ and $H D D$ and between-state variation in the $C D D I$ and $H D D I$.

According to Prediction 3 of my model, the effects of both the hotter and the colder climates are expected to be more pronounced at the higher income levels. Thus, I include a three-way interaction of $C D D, C D D I$ and $\ln G D P P C$ in summers and $H D D, H D D I$

\footnotetext{
${ }^{10} \mathrm{~A}$ major holiday is one that is declared to be a holiday for all government employees (on account of national or religious events). Minor holidays are the 2 additional days of holidays that government employees are entitled to select for minor religious festivals from a list of scheduled holidays.
} 
and $\ln G D P P C$ in winters to study the impact of income on the climate sensitivity of electricity demand in India. In other words, income and climate will interact to determine the temperature sensitivity of the electricity demand in a given state. To evaluate this hypothesis, I estimate Model C as:

$$
\begin{aligned}
\ln \left(E d_{i d}\right)= & \theta_{i}+\kappa_{Q}+v_{w}+v \prime X_{i d} \\
& +\alpha_{1} H D D_{i d} * H D D I_{i}+\beta_{1} C D D_{i d} * C D D I_{i} \\
& +\alpha_{2} H D D_{i d} * H D D I_{i} * \ln \left(G D P P C_{i t}\right) \\
& +\beta_{2} C D D_{i d} * C D D I_{i} * \ln \left(G D P P C_{i t}\right)+\varepsilon_{i d}
\end{aligned}
$$

The marginal effect of daily temperature on the log of electricity demand is $\alpha_{1} * H D D I_{i}$ $+\alpha_{2} H D D I_{i} * \ln \left(G D P P C_{i t}\right)$ if $T_{i d} \leq 20.3^{0} C$ and $\eta_{1} * C D D I_{i}+\eta_{2} * C D D I_{i} * \ln \left(G D P P C_{i t}\right)$ if $T_{i d}>20.3^{0} C$. We expect $\alpha_{2}<0$ and $\eta_{2}>0$.

For robustness checks, I estimate a less restrictive model using region fixed-effects instead of state fixed-effects. I estimate Model D as:

$$
\begin{aligned}
\ln \left(E d_{i d}\right)= & R_{i}+\kappa_{Q}+v_{w}+v \prime Z_{i d} \\
& +\alpha_{1} H D D_{i d} * H D D I_{i}+\eta_{1} C D D_{i d} * C D D I_{i} \\
& +\alpha_{2} H D D_{i d} * H D D I_{i} * \ln \left(G D P P C_{i t}\right) \\
& +\eta_{2} C D D_{i d} * C D D I_{i} * \ln \left(G D P P C_{i t}\right)+\varepsilon_{i d}
\end{aligned}
$$

where $Z$ includes all controls in $X$ and two additional regressors, the proportion of villages electrified, and the share of industry in the gross domestic product of a state. $R_{i}$ captures unobserved region-level heterogeneity by region fixed-effects. It accounts for factors which are fixed for a region over time. This model is likely to suffer from omitted variable bias as there are factors such as state-specific policies that may also be correlated with other explanatory variables such as income which may influence electricity demand significantly though this model does not account for them. The key advantage of this model is that it estimates coefficients using variation across states within a region, and variation within states over time. This would result in more precise estimates for the variables which are observed annually such as GDPPC, population, and price as the variation within a state over time is relatively much less than variation across states. 


\section{Regression Results}

Table (2) summarizes results from all the models. The Table shows the marginal effects and associated standard errors of all the variables at sample means. Table A1 in the appendix reports the full estimation results. I use a range of models in order to explore the sensitivity of calculated coefficients to the equation specification. All models are estimated by ordinary least squares OLS. I report Newey-West type standard errors by Driscoll and Kraay (1998) that allow for autocorrelated and cross-sectionally correlated errors of the general form.

Column (1) of Table (2) reports the estimates of the basic model without interactions as in eq(1). In column (2), I interact HDD with the HDDI and CDD with the CDDI and estimate eq(2). In addition to the weather and climate interaction in column (2), column (3) adds the interaction of HDD with the HDDI and GDPPC and CDD with the CDDI and GDPPC to estimate eq(3). Column (4) estimates a region fixed-effects model as in $\mathrm{eq}(4)$. The $\mathrm{R}^{2}$ value in all models is essentially unity; however, this is an artifact of the inclusion of state or region dummies. I prefer the full interacted state fixed-effect Model $\mathrm{C}$ over other models as it has the lowest standard errors for most of the coefficients. For

purposes of robustness checks, I also estimated (but do not report for brevity) models with state-by-quarter fixed-effects and state-specific trends and find the results of the study to remain substantively unchanged.

Of primary interest here is the impact of change in the weather (CDD, HDD) and climate (HDDI, CDDI) on electricity demand. The basic results remain similar across models although in the more restricted state fixed-effect models (column (1-3)), the coefficients and standard errors of weather and climate variables are smaller than those in the region fixed-effects regression (column (4)), suggesting that unobserved state differences (for e.g., state-specific policies) may have biased the parameter estimates in the column (4).

As discussed above, the impact of temperature on electricity demand is non-linear with the slope going from negative or zero at low temperatures to positive impacts with increases in temperature. This pattern is borne out clearly in Table (2). The impact of a $1^{0} C$ change in temperature in winters (when temperature is below $20.3^{0} \mathrm{C}$ ) is small but negative and significant across all specifications. The impact of a $1^{0} C$ change in temperature in summers (when temperature is above $20.3^{\circ} C$ ) is large and positive and significant across all specifications.

The magnitude of the coefficient of the CDD exceeds the coefficient of the HDD in all the models. The results indicate a seasonal heterogeneity in how people will respond to climate change along intensive margins of adjustment. For example, for the preferred Model $\mathrm{C}$ of this study, a $1^{0} \mathrm{C}$ increase in temperature in summer increases expected daily electricity demand 
Table 2: Marginal Effect of Determinants of Electricity Demand at Sample Mean

\begin{tabular}{|c|c|c|c|c|}
\hline & \multicolumn{3}{|c|}{ State Fixed-Effect } & \multirow{2}{*}{$\frac{\text { Region Fixed-Eff }}{(4)}$} \\
\hline & (1) & $(2)$ & (3) & \\
\hline & Model A & Model B & Model C & Model D \\
\hline \multicolumn{5}{|l|}{ " VARIABLES } \\
\hline \multicolumn{5}{|l|}{ Key Variables } \\
\hline HDD & $\begin{array}{c}-0.00586^{* * * *} \\
(0.000994)\end{array}$ & $\begin{array}{c}-0.00111^{* * *} \\
(0.000246)\end{array}$ & $\begin{array}{c}-0.00162^{* * *} \\
(0.000236)\end{array}$ & $\begin{array}{c}-0.0152^{* * * *} \\
(0.000711)\end{array}$ \\
\hline CDD & $\begin{array}{l}0.0196^{* * *} \\
(0.000911)\end{array}$ & $\begin{array}{l}0.0147^{* * *} \\
(0.000876)\end{array}$ & $\begin{array}{l}0.0145^{* * *} \\
(0.000839)\end{array}$ & $\begin{array}{l}0.0196^{* * *} \\
(0.000872)\end{array}$ \\
\hline CDDI & & $\begin{array}{c}0.00554^{* * *} \\
(0.000330)\end{array}$ & $\begin{array}{c}0.00544^{* * *} \\
(0.000316)\end{array}$ & $\begin{array}{c}0.00736^{* * *} \\
(0.000328)\end{array}$ \\
\hline HDDI & & $\begin{array}{c}0.00135^{* * *} \\
(0.000298)\end{array}$ & $\begin{array}{c}0.00197^{* * *} \\
(0.000286)\end{array}$ & $\begin{array}{l}0.0184^{* * *} \\
(0.000862)\end{array}$ \\
\hline $\log (\mathrm{GDPPC})$ & $\begin{array}{l}1.130^{* * *} \\
(0.0212)\end{array}$ & $\begin{array}{l}1.132^{* * *} \\
(0.0208)\end{array}$ & $\begin{array}{l}1.131^{* * *} \\
(0.0192)\end{array}$ & $\begin{array}{l}.706^{* * *} \\
(.0069)\end{array}$ \\
\hline Control Variables & & & & \\
\hline Log(Population) & $\begin{array}{c}0.109 \\
(0.104)\end{array}$ & $\begin{array}{c}0.111 \\
(0.113)\end{array}$ & $\begin{array}{l}0.168^{* *} \\
(0.0817)\end{array}$ & $\begin{array}{l}0.883^{* * *} \\
(0.00430)\end{array}$ \\
\hline Log(Price) & $\begin{array}{c}0.0114 \\
(0.0102)\end{array}$ & $\begin{array}{c}0.0125 \\
(0.0109)\end{array}$ & $\begin{array}{c}0.0104 \\
(0.0106)\end{array}$ & $\begin{array}{c}-0.188^{* * *} \\
(0.00815)\end{array}$ \\
\hline MIIP & $\begin{array}{c}1.51 \mathrm{e}-05^{* * *} \\
(2.17 \mathrm{e}-06)\end{array}$ & $\begin{array}{c}1.80 \mathrm{e}-05^{* * *} \\
(2.27 \mathrm{e}-06)\end{array}$ & $\begin{array}{c}1.88 \mathrm{e}-05^{* * *} \\
(2.34 \mathrm{e}-06)\end{array}$ & $\begin{array}{c}2.01 \mathrm{e}-05^{* * *} \\
(2.29 \mathrm{e}-06)\end{array}$ \\
\hline \% Villages Elect & & & & $\begin{array}{c}0.00984^{* * *} \\
(0.000112)\end{array}$ \\
\hline Industry Share & & & & $\begin{array}{l}0.0257^{* * *} \\
(0.000403)\end{array}$ \\
\hline Major Holiday & $\begin{array}{l}0.000923 \\
(0.00382)\end{array}$ & & $\begin{array}{c}0.00223 \\
(0.00368)\end{array}$ & $\begin{array}{c}-0.0157^{* * *} \\
(0.00542)\end{array}$ \\
\hline Log(Agr_Pumpsets) & $\begin{array}{l}0.0100^{* *} \\
(0.00487)\end{array}$ & $\begin{array}{c}0.00986^{* *} \\
(0.00502)\end{array}$ & $\begin{array}{c}0.0122^{* * * *} \\
(0.00420)\end{array}$ & $\begin{array}{c}0.0400^{* * *} \\
(0.00272)\end{array}$ \\
\hline Rainfall_Weeksum & $\begin{array}{c}-0.000506^{* * *} \\
(4.58 \mathrm{e}-05)\end{array}$ & $\begin{array}{c}-0.000522^{* * *} \\
(4.63 \mathrm{e}-05)\end{array}$ & $\begin{array}{c}-0.000465 * * * \\
(4.67 \mathrm{e}-05)\end{array}$ & $\begin{array}{c}-0.000387 * * * \\
(8.94 \mathrm{e}-05)\end{array}$ \\
\hline Obser & 50,932 & 50,932 & 50,932 & 50,932 \\
\hline $\mathrm{R}$-squ & 0.993 & 0.993 & 0.994 & 0.97 \\
\hline State FE & YES & YES & YES & NO \\
\hline Quarter FE & YES & YES & YES & YES \\
\hline Day of Week FE & YES & YES & YES & YES \\
\hline Region FE & NO & NO & NO & YES \\
\hline
\end{tabular}

Driscoll and Kraay (1998) Standard errors in parentheses ${ }^{* * *} \mathrm{p}<0.01,{ }^{* *} \mathrm{p}<0.05,{ }^{*} \mathrm{p}<0.1$ 
by 1.5 per cent (as a result of greater usage of cooling equipment) while a $1^{0} C$ increase in temperature in winter reduces electricity demand by about 0.2 percent (due to lower usage of heating equipment) at the sample mean of income and climate.

The response to the CDDI and HDDI captures the adjustment along the extensive margin due to climate change. Across specifications, the marginal impacts of CDDI and HDDI are positive and significant. For my preferred specification (Model C), I estimate an average of a 0.5 percent and 0.2 percent increase in electricity demand for a 100-degree day increase in the CDDI and HDDI, respectively. In Model D, the marginal effect is slightly higher at 0.7 percent for the CDDI (with the same standard error as in Model C) whereas it is significantly higher at 1.8 percent for the HDDI (though very noisy).

The results provide useful insights on how the intensive adjustments may depend on the extensive adjustments due to climate change. In Model B, when I include only the two-way interaction term of CDD and CDDI in summers and HDD and HDDI in winters, both the interactions are significant and have the expected signs. The interaction of CDD with CDDI is positive signifying that a hotter climate will lead to more space-cooling equipment and higher temperature sensitivity. The interaction of HDD with HDDI is negative signifying that the colder climate will lead to more space-heating equipments and higher negative temperature sensitivity.

In Models $\mathrm{C}$ and $\mathrm{D}$, the interaction of the CDD with the gross domestic income per capita and CDDI is positive and significant at the $\mathrm{p}<.01$ level. The sizes of the coefficients suggest that the interaction effect of the CDDI with income that I have identified is quite large. Thus, I expect the effects of hotter climate to be more pronounced at the higher income levels. The interaction of the HDD with the gross domestic income per capita and HDDI is negative and significant at the $\mathrm{p}<.11$ level in Model C. Model D (estimated with region fixed effects), which includes both the two-way interaction of HDD and HDDI and the three-way interaction of HDD, HDDI and income, lead to a positive and significant coefficient on the three-way interaction term. This may indicate misspecification in the model as the variation in the HDDI is less (with many states having zero HDDI) and it may not be enough to estimate this effect. Thus, I drop the three-way interaction of HDD, GDPPC and HDDI in Model D to get meaningful estimates of the coefficients.

Although these results provide good insight into the magnitude and importance of each interaction effect, a visual inspection of the marginal effect of temperature at various combinations of climate and income may be more helpful in recognizing the presence of interactions. Figures (3) and (4) present the temperature sensitivity in summers and winters, respectively, from Model C. At the mean income (INR 29,234) and CDDI of 2000, a 1 degree increase in temperature in summer increases expected daily electricity demand by about 1.6 per cent. 


\section{Figure 3:}

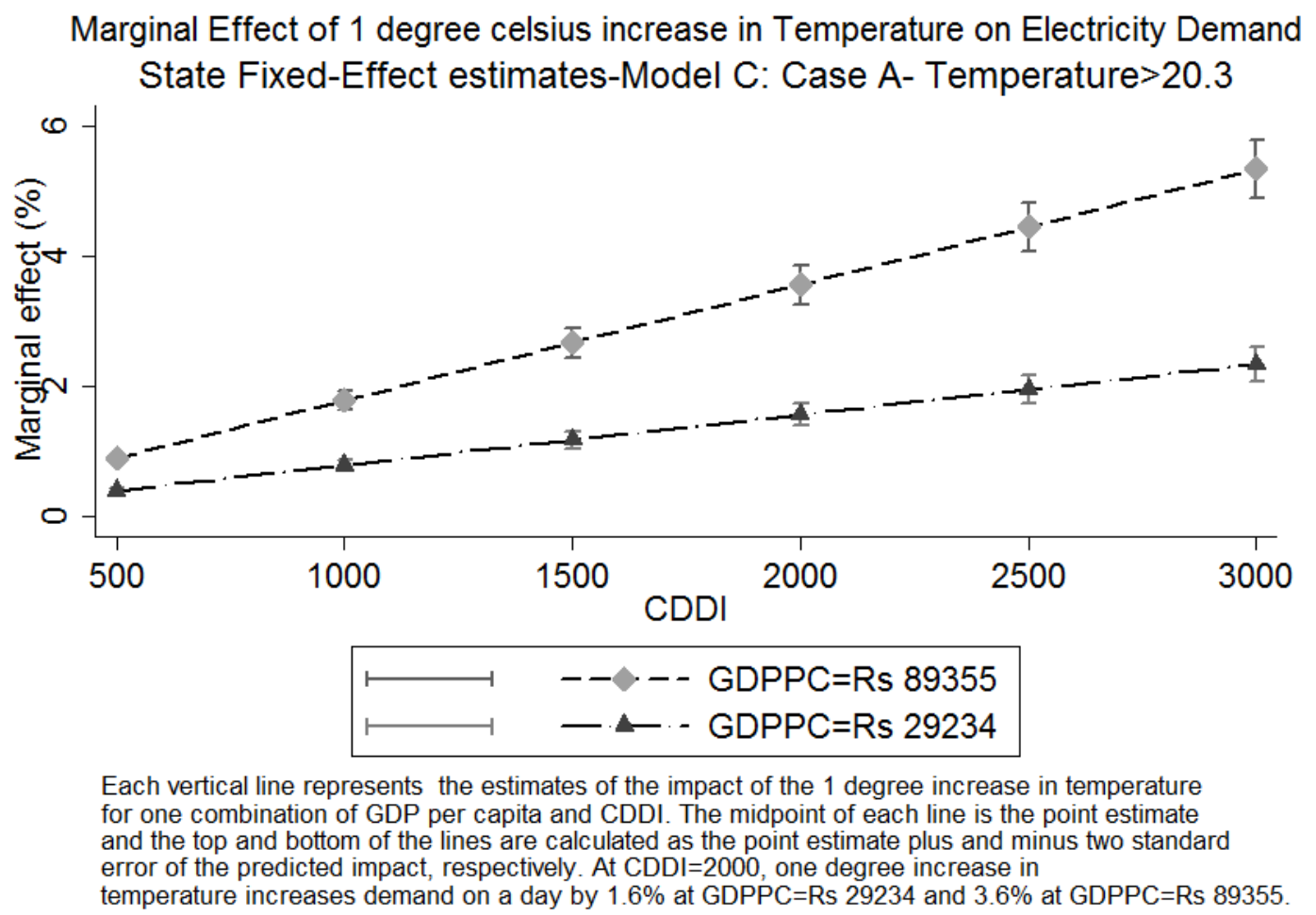

At the highest level of income (INR 89,355) in the sample and CDDI of 2000, a 1 degree increase in temperature in summer increases expected daily electricity demand by about 3.6 per cent. At the mean income (INR 29,234) and HDDI of 500, a 1 degree increase in temperature in winter decreases expected daily electricity demand by about 0.2 per cent. At the highest level of income (INR 89,355) in the sample and HDDI of 500, a 1 degree increase in temperature in winter decreases expected daily electricity demand by about 0.4 per cent.

I draw the following conclusions based on the above results. The degree to which electricity demand in a given state is sensitive to changes in climate will depend both on its climate type and on the level of its economic development. As people's standard of living improves, their use of air conditioners and other temperature-controlling equipment tool will increase, thus increasing their sensitivity to climate change. As discussed earlier, the overall impact of climate change will be jointly determined by both intensive and extensive adjustments. The study finds that the interaction of income with the CDDI and CDD in summers has a much higher impact on electricity demand than the interaction of income with the HDDI and HDD in winters. As income determines how people adapt to climate change, both global warming and income growth will have asymmetric effects on electricity consumption in summers and winters. The results also indicate that an increase in temperature in summers has an im- 
Figure 4:

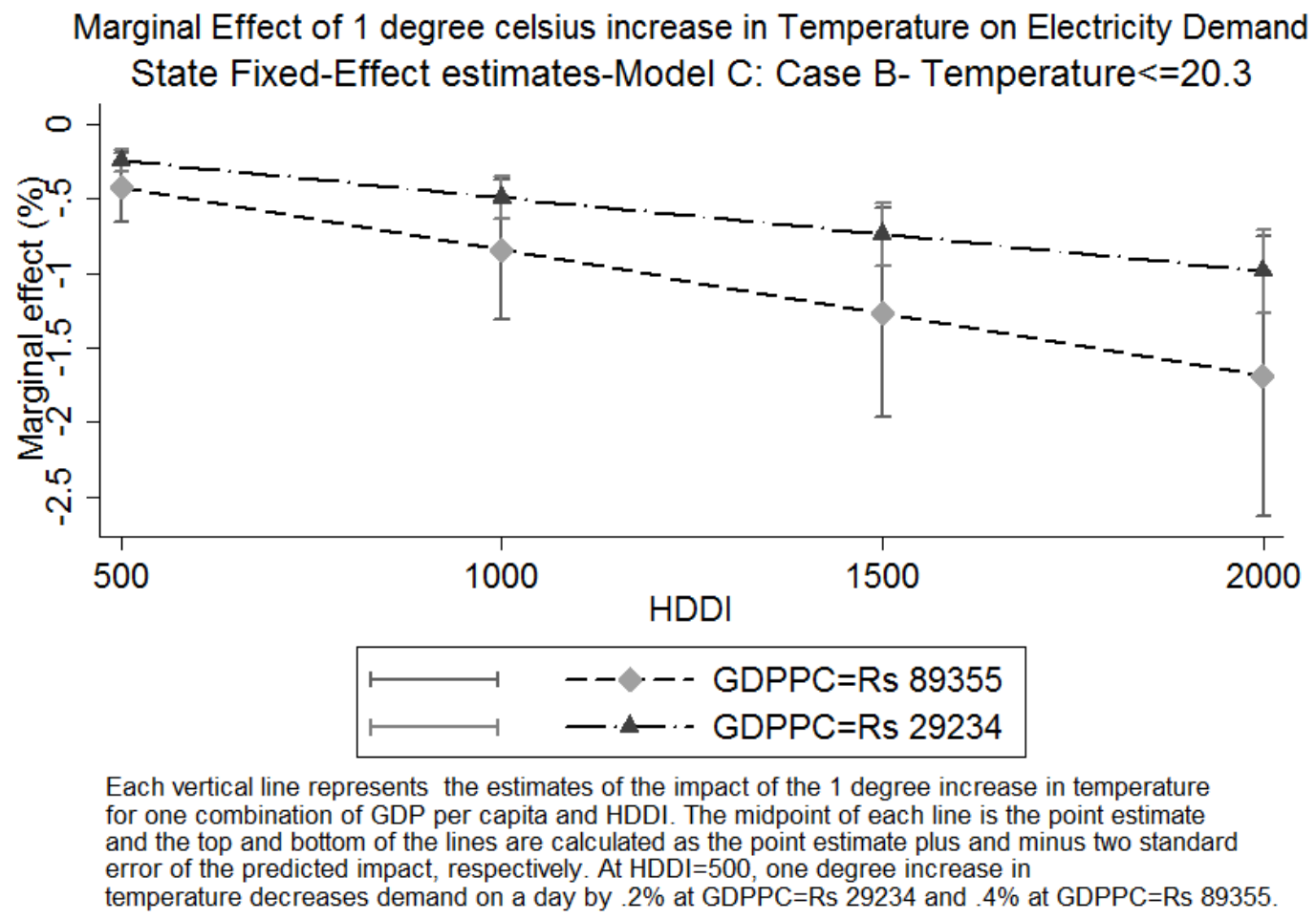

pact on electricity consumption which is seven times the size of the impact of an equivalent increase in temperature on electricity consumption in winters and that an increase in net electricity demand would therefore be the likely result of climate change.

The control variables in Table (2) provide a rich set of results in and of themselves. The coefficients of the socio-economic variables such as GDPPC, population, price and pumpsets turn out to be more precise with much smaller standard errors in the region fixed-effects regression than the state fixed-effects regressions. The reason is the much larger variance in the socio-economic variables across states within a region than within a state over time, which results in greater residual variation and more precise estimates in the region fixed-effect model than in the state fixed-effect model.

Electricity demand is higher in the wealthier states than in the poorer states. A 1 percent increase in income per capita results in about 1-0.7 percent increase in daily electricity demand in most models. Interestingly, the elasticity of electricity demand with respect to GDPPC is higher than elasticity of electricity demand with respect to temperature and climate. As expected, price has a significant negative impact and population has a significant positive impact on electricity demand in the region fixed-effects regression. A 1 percent higher electricity price results in about 0.2 percent decrease in daily electricity demand. A 1 percent 
increase in population results in almost 0.9 percent increase in the daily electricity demand of a state. As expected, in the state fixed-effect models, price and population (with a small, within-state variation) turns out to be insignificant in most models. Most models suggest that higher the use of agricultural pumpsets higher the electricity demand; that rainfall has a significant negative impact on electricity demand; that the interaction of pumpsets with accumulated rainfall in the last thirty days is negative and significant; that on holidays, Saturdays and Sundays, expected electricity demand is estimated to be somewhat lower than the average level; that the index of industrial seasonality has a positive impact on electricity demand; that an increase in the proportion of villages electrified results in an increase in electricity demand; that higher industrial share in the income of a state increases electricity demand.

\section{Impact of Climate Change on Electricity Demand}

In this section, I explore the effect of predicted climate change on electricity demand. I calculate the predicted impact on electricity demand for each state as a difference between predicted electricity demand under the reference scenario of no climate change and the predicted electricity demand under the climate change scenario for two time-periods, shortterm (2030) and mid-term (2050). I then sum each state's change in electricity demand to calculate the impact on India. Although these short- and mid-term predictions have important implications for analyzing the impact of global warming on electricity demand because they are based on available data for the past five-years, these long-term forecasts may not carry a very high degree of precision. In an uncertain world, the underlying assumptions of our predictions may not hold true till 2030 and 2050. Hence, the results obtained in this study should not be interpreted as exact forecasts but as roughly indicative of the direction and magnitude of the effects that might be expected from climate change on electricity demand.

According to the fifth assessment report by the Intergovernmental Panel on Climate Change (IPCC), the mean surface temperature increase in South Asia is likely be in the range of $1^{\circ} \mathrm{C}$ to $1.5^{\circ} \mathrm{C}$ (medium confidence) for the period 2016-2035 (relative to 1986-2005) and in the range of $1.5-3^{\circ} \mathrm{C}$ (medium confidence) for the period $2046-2065$. In line with these scenarios, for the purposes of projections in this paper, I consider a uniform increase of $1^{\circ} \mathrm{C}$ in the mean temperature for 2030 and a uniform increase of $2^{\circ} \mathrm{C}$ in the mean temperature for 2050. I apply these scenarios uniformly by season and region to India in the calculations that follow. In addition to these two uniform scenarios, I also predict the future electricity demand under the reference scenario of no climate change. 
I consider two different scenarios for future growth in the gross domestic product of India: a) the target average growth rate in the twelfth Five-Year Plan of 6 percent per year from 2010 to 2050; b) average annual growth rate of 4 percent per year from 2010 to 2050 . I assume population to grow at an average annual rate of 1.1 percent per year (medium UNDP scenario). I assume that the individual states will grow at a rate that will enable them to maintain their share in India's GDP at the same mean share rate as during the 2005-2009 period. I assume the same for future state population projections. The percentage of villages electrified, the number of agricultural pumpsets and the share of the industry in the state's GDP in each state increase linearly between 2010 and 2050 at the rate achieved during 20052009. For other predictor variables such as-rainfall, prices, holiday and week day dummy, and industrial seasonality index (MIIP), I assume the same values as in 2009.

Between 2009 and 2030, India's GDP will double if it grows at the 4 percent p.a. and treble if it grows at 6 percent p.a. According to the preferred Model $\mathrm{C}$ of this study, in a reference scenario with no climate change, electricity demand in India is expected to double (that is, increase by 105 percent) between 2009 and 2030 with 4 percent p.a. GDP growth and more than treble (i.e., increase by 224 percent) with 6 percent p.a. GDP growth. Between 2009 and 2050, India's GDP will increase by a factor of 4 if it grows at 4 percent p.a. and by a factor of 10 if it grows at 6 percent p.a. The electricity demand is expected to become 4 times (i.e., increase by the factor of 3) with 4 percent p.a. GDP growth and 10 times (i.e., increase by the factor of 9 ) with 6 percent p.a. GDP growth by 2050 .

Estimates of the impact of climate change: Results from the two models (C and D) are given in Table(3). Although climate change will happen in future, I present climate change impacts for the 2009 economy in order to compare the impacts with the richer economies of 2030 and 2050. The study finds that the climate sensitivity of electricity demand in India is likely to be highly sensitive to income growth. In 2009, I expect a 1 degree increase in the mean temperature to result in about 4-6 percent increase in the electricity demand over the reference scenario of no climate change. In 2030, I expect a 1 degree increase in the mean temperature to result in about 7-9 percent increase in the electricity demand over the reference scenario with a 4 percent growth in the GDP and about 9-12 percent increase in the electricity demand over the reference scenario with a 6 percent growth in the GDP. In the most likely scenario of a mean temperature increase of about $2^{0} \mathrm{C}$ by 2050 , I expect electricity demand to rise about about 22-29 percent higher with a 4 percent growth in the GDP and about 31-43 percent higher over the reference scenario with a 6 percent growth in the GDP. In 2030 and 2050, India will be a much richer economy; thus, I predict the impact of a 1 degree increase in the mean temperature to be accordingly higher in comparison with 2009. 
Table 3: Predicted Impact of Climate Change on Electricity Demand State Fixed Effect (Model C) Region Fixed Effect (Model D)

\begin{tabular}{ccccccc}
\hline & & & \multicolumn{4}{c}{ GDP growth p.a from 2009 } \\
\hline Year & $\begin{array}{c}\text { Intensive(I) / } \\
\text { Extensive (E) }\end{array}$ & Scenario & $4 \%$ & $6 \%$ & $4 \%$ & $6 \%$ \\
\hline \hline 2009 & $\mathrm{I}$ & $1^{0} c$ & 2 & 2 & 2.5 & 2.5 \\
2009 & $\mathrm{I}+\mathrm{E}$ & $1^{0} \mathrm{c}$ & 4.4 & 4.4 & 5.9 & 5.9 \\
2030 & $\mathrm{I}$ & $1^{0} \mathrm{c}$ & 3 & 3.7 & 3.8 & 4.9 \\
2030 & $\mathrm{I}+\mathrm{E}$ & $1^{0} \mathrm{c}$ & 6.9 & 8.6 & 8.95 & 11.6 \\
2050 & $\mathrm{I}+\mathrm{E}$ & $1^{0} \mathrm{c}$ & 9.4 & 13 & 12.1 & 17.7 \\
2050 & $\mathrm{I}+\mathrm{E}$ & $2^{0} \mathrm{c}$ & 21.6 & 30.7 & 28.5 & 43
\end{tabular}

Table(3) also presents the contributions of intensive and extensive adjustments separately in the event of an increase in total electricity demand due to climate change for the years 2009 and 2030. i obtain the contribution of intensive adjustments by allowing the temperature distribution to change where the CDD and HDD on each day is increased by $1^{0} c$ holding the CDDI and HDDI constant. The results suggest that the contribution of extensive adjustments is somewhat higher than that of intensive adjustments. Also the share of extensive adjustments in total climate impacts increases with the level of income. For example, according to the preferred Model $\mathrm{C}$ of my study, the share of extensive adjustments in total impacts is about 54 percent in 2009 and 57 percent in 2030 (in the 6 percent growth scenario). Of the total increase in electricity demand of 8.6 percent over the reference scenario in 2030 under the 6 percent GDP growth scenario, I predict a 3.7 percent increase due to intensive adjustments and 4.9 percent increase due to extensive adjustments. Thus, extensive adjustments play an important role in determining the impact of climate change on electricity demand in India. The results of the study suggest that electricity demand models that do not account for extensive adjustments are likely to underestimate the climate change impacts on electricity demand, especially in developing countries like India, where the current penetration of space conditioning equipment is very low.

The extent of climate change effects on individual states will depend on their climate type and level of income. Thus, Delhi, Chandigarh, Gujarat, Maharashtra, Haryana, Punjab, Kerala, Karnataka, Andhra Pradesh and Tamil Nadu can be categorized as relatively rich and hot states with above average gross domestic product per capita and cooling degree days. Bihar, Jharkhand, Orissa, Uttar Pradesh, Madhya Pradesh, Rajasthan, Chhattisgarh and West Bengal, on the other hand, are relatively hot but poor states with above average cooling degree days and below average gross domestic product per capita. Himachal Pradesh with above average gross domestic product per capita and above average heating degree days 
is a relatively rich and cold state. Uttarakhand and Jammu and Kashmir with below average gross domestic product per capita and above average heating degree days are relatively poor and cold states. Figures (5) and (6) show the predicted climate change impacts by state across India in 2030 .

The five rich and hot states-Delhi, Maharashtra, Gujarat, Andhra Pradesh and Tamil Nadu-will therefore be the most affected in terms of electricity demand due to climate change with an estimated impact of 11-17 percent. The next most affected group includes Karnataka, Kerala, Haryana, Orissa and Chandigarh with the estimated impact at 8-12 percent. The third most affected group comprises poor and hot states such as Bihar, Jharkhand, Uttar Pradesh, Madhya Pradesh and all north-eastern states with the estimated impacts at 3-10 percent. The least affected states are the three cold states-Jammu and Kashmir, Himachal Pradesh, and Uttarakhand. Jammu and Kashmir turns out to be the only state the net electricity demand of which reduces by 1-5.5 percent due to climate change in 2030 . In the case of Himachal Pradesh and Uttarakhand, there will be an increase in electricity demand but it would be less than 2 percent.

\section{Conclusion}

The empirical evidence from India in this study suggests that the climate sensitivity of electricity demand in a developing country is likely to be highly sensitive to income growth. I use a state-level panel dataset to estimate the effect of daily temperature (a key indicator of weather) and long-term climate on electricity demand which is conditional on state or region fixed-effects. My preferred estimates, using a 1 degree Celsius uniform climate change scenario, indicate that climate change will increase electricity demand by 6.9 percent with 4 percent p.a. GDP growth and by 8.6 percent with 6 percent p.a. GDP growth in 2030 over the reference scenario of no climate change. This reflects the fact that the estimated marginal effect of a hotter climate on electricity demand is greater when income is higher among the populace than otherwise. It points to the critical need to engage in electricity demand management and boost efficiency in use of electricity to become a low-energy consuming society in the future. 
Figure 5:

\section{State Fixed Effect Estimates: Model C Predicted Impacts of Climate Change in 2030}

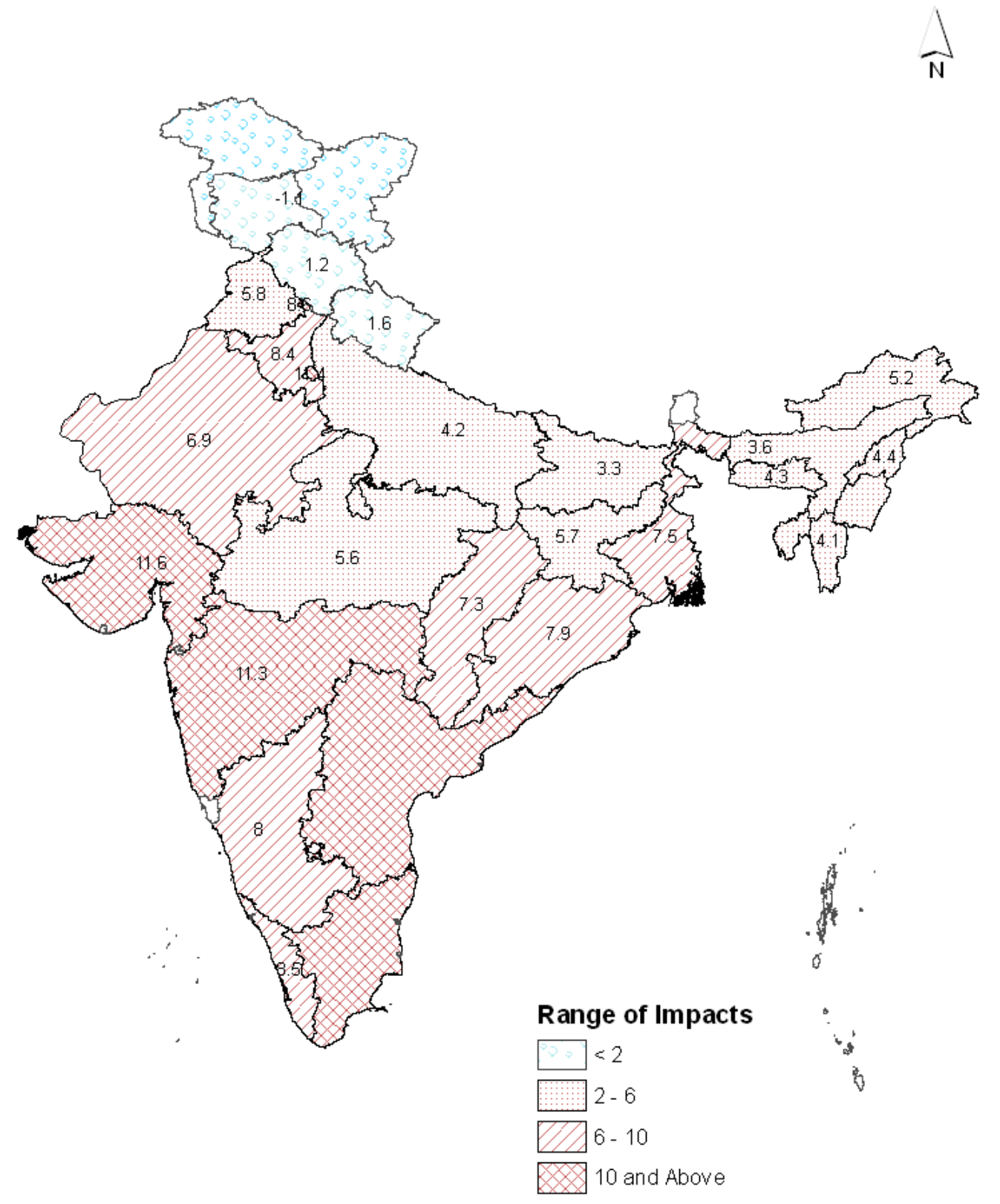


Figure 6:

\section{Region Fixed Effect Model Estimates: Model D Predicted Impacts of Climate Change in 2030}

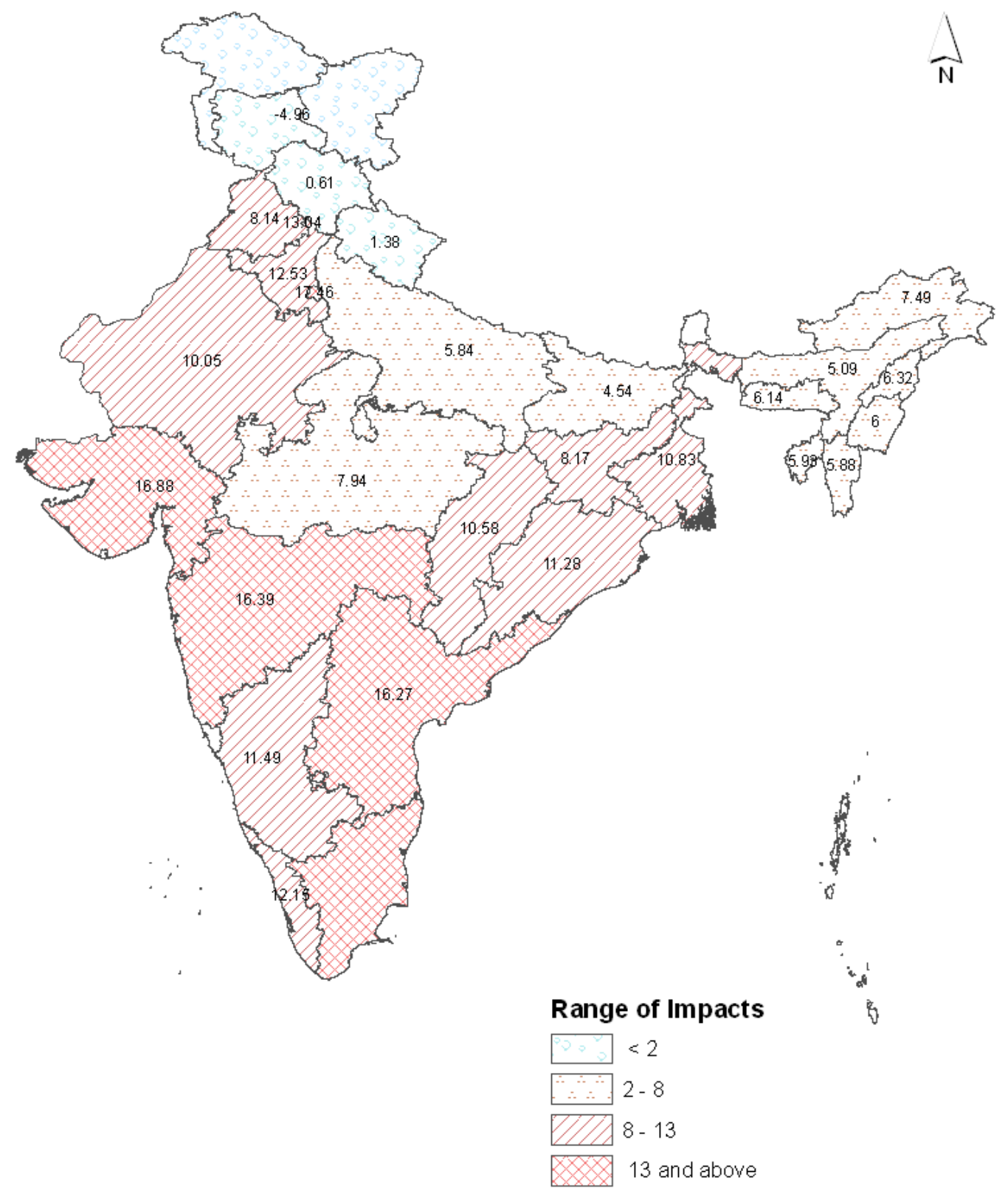


The rapid increase in electricity demand due to climate change results from both intensive and extensive adjustments in heating and cooling requirements. The findings of the study suggest that over 50 percent of the climate change impacts will be due to extensive adjustments. This highlights the importance of potential interactions between increasing cooling degree days and increasing incomes, and the impact of the resulting long-term adjustments (such as the higher penetration of air cooling devices) on the electricity sector. Electricity demand models that do not account for extensive adjustments are likely to underestimate the climate change impacts on electricity demand, especially in developing countries like India where the current penetration of space conditioning equipment is very low.

Additionally, the analysis indicates considerable heterogeneity in the predicted impacts across states. The nature and extent of the impacts will vary geographically, depending on the climate and development status of the states. Thus, the states to be most affected by climate change will be the rich and hot states. Further, research using data from other countries and sectors would prove extremely useful in helping us understand not just how climate and income changes in the future may impact electricity demand but also how historic climatic and income differences across different parts of the world may have contributed to existing differences in electricity demand between nations.

\section{Appendix Tables}


Table 4: Estimates of Electricity demand Models 2005-2009

\begin{tabular}{|c|c|c|c|c|}
\hline & \multicolumn{3}{|c|}{ State Fixed-Effect } & \multirow{2}{*}{$\frac{\text { Region Fixed-Effect }}{(4)}$} \\
\hline & (1) & $(2)$ & (3) & \\
\hline & Model A & Model B & Model C & Model F \\
\hline VARIABLES & & & & \\
\hline $\log (\mathrm{GDPPC})$ & $1.130^{* * *}$ & $1.132^{* * *}$ & $1.019^{* * *}$ & $0.551^{* * *}$ \\
\hline & $(0.0212)$ & $(0.0208)$ & $\begin{array}{l}(0.0191) \\
0168 * *\end{array}$ & $\begin{array}{l}(0.00882) \\
0.883 * * *\end{array}$ \\
\hline Log(Population) & $\begin{array}{c}0.109 \\
(0.104)\end{array}$ & $\begin{array}{c}0.111 \\
(0.113)\end{array}$ & $\begin{array}{l}0.168^{N *} \\
(0.0817)\end{array}$ & $\begin{array}{l}0.883^{\text {*** }} \\
(0.00430)\end{array}$ \\
\hline $\log ($ Price $)$ & 0.0114 & 0.0125 & 0.0104 & $-0.188^{* * *}$ \\
\hline & $(0.0102)$ & $(0.0109)$ & $(0.0106)$ & $(0.00815)$ \\
\hline Log(Agr_Pumpsets) & $0.0115^{* *}$ & $0.0118^{* *}$ & $0.0140^{* * *}$ & $0.0454^{* * *}$ \\
\hline MUP & $\begin{array}{c}(0.00484) \\
1.51{ }_{-} 05 * * *\end{array}$ & $\begin{array}{c}(0.00502) \\
1800-05 * * *\end{array}$ & $\begin{array}{c}(0.00418) \\
188 e_{-0} 5^{* * *}\end{array}$ & $\begin{array}{c}(0.00268) \\
2010-05 * * *\end{array}$ \\
\hline $\mathrm{MHIP}$ & $\begin{array}{c}1.51 \mathrm{e}-05^{2} \\
(2.17 \mathrm{e}-06)\end{array}$ & $\begin{array}{c}1.80 \mathrm{e}-05 \\
(2.27 \mathrm{e}-06)\end{array}$ & $\begin{array}{l}1.8 \mathrm{e}-05 \\
(2.34 \mathrm{e}-06)\end{array}$ & $\begin{array}{l}\left(2.01 \mathrm{e}-05^{-}\right. \\
(2.06)\end{array}$ \\
\hline Major Holiday & $\begin{array}{l}0.000923 \\
(0.00382)\end{array}$ & $\begin{array}{c}0.00161 \\
(0.00378)\end{array}$ & $\begin{array}{c}0.00223 \\
(0.00368)\end{array}$ & $\begin{array}{c}-0.0157^{* * *} \\
(0.00542)\end{array}$ \\
\hline lpump_rainsum7 & $\begin{array}{c}-4.85 \mathrm{e}-05^{* * *} \\
(1.11 \mathrm{e}-05)\end{array}$ & $\begin{array}{c}-6.03 \mathrm{e}-05^{* * *} \\
(1.12 \mathrm{e}-05)\end{array}$ & $\begin{array}{c}-5.72 \mathrm{e}-05^{* * *} \\
(1.12 \mathrm{e}-05)\end{array}$ & $\begin{array}{c}-0.000169 * * * \\
(1.68 \mathrm{e}-05)\end{array}$ \\
\hline Rainfall_Weeksum & $\begin{array}{l}-1.34 \mathrm{e}-05 \\
(0.000113)\end{array}$ & $\begin{array}{c}8.99 \mathrm{e}-05 \\
(0.000111)\end{array}$ & $\begin{array}{c}0.000117 \\
(0.000112)\end{array}$ & $\begin{array}{c}0.00133 * * * \\
(0.000177)\end{array}$ \\
\hline HDD & $\begin{array}{c}-0.00586^{* * *} \\
(0.000994)\end{array}$ & & & \\
\hline CDD & $\begin{array}{l}0.0196^{* * *} \\
(0.000911)\end{array}$ & & & \\
\hline HDDI*HDD & & $\begin{array}{c}-0.000337^{* * *} \\
(7.46 \mathrm{e}-05)\end{array}$ & $\begin{array}{c}0.00250 \\
(0.00192)\end{array}$ & $\begin{array}{c}-0.00230^{* * *} \\
(0.000108)\end{array}$ \\
\hline $\mathrm{CDDI}^{*} \mathrm{CDD}$ & & $\begin{array}{c}0.000791^{* * *} \\
(4.71 \mathrm{e}-05)\end{array}$ & $\begin{array}{c}-0.00772^{* * *} \\
(0.000433)\end{array}$ & $\begin{array}{r}-0.0111^{* * *} \\
(0.000538)\end{array}$ \\
\hline $\begin{array}{l}\text { HDDI*HDD } \\
{ }^{*} \log (\mathrm{GDPPC})\end{array}$ & & & $\begin{array}{r}-0.000293^{+} \\
(0.000188)\end{array}$ & \\
\hline $\mathrm{CDDI}^{*} \mathrm{CDD}$ & & & $0.000833^{* * *}$ & $0.00120 * * *$ \\
\hline${ }^{*} \log (\mathrm{GDPPC})$ & & & $(4.34 \mathrm{e}-05)$ & $(5.28 \mathrm{e}-05)$ \\
\hline$\%$ Villages elect & & & & $\begin{array}{c}0.00984^{* * *} \\
(0.000112)\end{array}$ \\
\hline Industry share & & & & $\begin{array}{l}0.0257 * * * \\
(0.000403)\end{array}$ \\
\hline Constant & $\begin{array}{c}-8.791^{* * *} \\
(1.770)\end{array}$ & $\begin{array}{c}-8.873^{* * *} \\
(1.955)\end{array}$ & $\begin{array}{c}-8.789^{* * *} \\
(1.429)\end{array}$ & $\begin{array}{c}-18.11^{* * *} \\
(0.116)\end{array}$ \\
\hline Observations & 50,932 & 50,932 & 50,932 & 50,932 \\
\hline R-squared & 0.993 & 0.993 & 0.994 & 0.97 \\
\hline State FE & YES & YES & YES & $\mathrm{NO}$ \\
\hline Quarter FE & YES & YES & YES & YES \\
\hline Day of Week FE & YES & YES & YES & YES \\
\hline Region FE & $\mathrm{NO}$ & $\mathrm{NO}$ & $\mathrm{NO}$ & YES \\
\hline
\end{tabular}




\section{References}

[Akpinar-Ferrand \& Singh, 2010] Akpinar-Ferrand, E. \& Singh, A. (2010). Modeling increased demand of energy for air conditioners and consequent emissions to minimize health risks due to climate change in india. Environmental Science \& $\mathcal{F}$ Policy, 13(8), 702-712.

[Al-Zayer \& Al-Ibrahim, 1996] Al-Zayer, J. \& Al-Ibrahim, A. A. (1996). Modelling the impact of temperature on electricity consumption in the eastern province of saudi arabia. Journal of Forecasting, 15(2), 97-106.

[Auffhammer \& Mansur, 2012] Auffhammer, M. \& Mansur, E. T. (2012). Measuring climatic impacts on energy expenditures: A review of the empirical literature.

[DePaula \& Mendelsohn, 2010] DePaula, G. \& Mendelsohn, R. (2010). Development and the impact of climate change on energy demand: Evidence from brazil. Climate Change Economics, 1(03), 187-208.

[Gupta, 2012] Gupta, E. (2012). Global warming and electricity demand in the rapidly growing city of delhi: A semi-parametric variable coefficient approach. Energy Economics, 34(5), 1407-1421.

[Mirasgedis et al., 2007] Mirasgedis, S., Sarafidis, Y., Georgopoulou, E., Kotroni, V., Lagouvardos, K., \& Lalas, D. (2007). Modeling framework for estimating impacts of climate change on electricity demand at regional level: case of greece. Energy Conversion and Management, 48(5), 1737-1750.

[Pardo et al., 2002] Pardo, A., Meneu, V., \& Valor, E. (2002). Temperature and seasonality influences on spanish electricity load. Energy Economics, 24(1), 55-70.

[Sailor, 2001] Sailor, D. J. (2001). Relating residential and commercial sector electricity loads to climateŮevaluating state level sensitivities and vulnerabilities. Energy, 26(7), 645-657.

[Sailor \& Muñoz, 1997] Sailor, D. J. \& Muñoz, J. R. (1997). Sensitivity of electricity and natural gas consumption to climate in the usaÜmethodology and results for eight states. Energy, 22(10), 987-998.

[Sailor \& Pavlova, 2003] Sailor, D. J. \& Pavlova, A. (2003). Air conditioning market saturation and long-term response of residential cooling energy demand to climate change. Energy, 28(9), 941-951. 
[Sivak, 2009] Sivak, M. (2009). Potential energy demand for cooling in the 50 largest metropolitan areas of the world: implications for developing countries. Energy Policy, $37(4), 1382-1384$.

[Valor et al., 2001] Valor, E., Meneu, V., \& Caselles, V. (2001). Daily air temperature and electricity load in spain. Journal of applied Meteorology, 40(8), 1413-1421.

[Wolfram et al., 2012] Wolfram, C., Shelef, O., \& Gertler, P. (2012). How Will Energy Demand Develop in the Developing World? Technical report, National Bureau of Economic Research. 